\title{
APPLICATION OF DISCRETE-EVENT SIMULATION IN HEALTH CARE : A PRELIMINARY STUDIES
}

\author{
Intan Berlianty ${ }^{1)}$, Yuli Dwi Astanti*2), Irwan Soejanto ${ }^{3)}$ \\ Jurusan Teknik Industri \\ Universitas Pembangunan Nasional Veteran Yogyakarta \\ Jl. Babarsari No 2 Tambakbayan Yogyakarta \\ Email : ${ }^{2}$ yulidwi.astanti@upnyk.ac.id
}

\begin{abstract}
Simulation is one of the tools to solve the problems in a system, including hospital systems. The hospital has objectives and entities that are different from other systems, namely service to patients (humans) primarily, so making some decisions requires consideration due to the complexity of the variables within them. This preliminary study will discuss what problems might occur in the hospital and how the application of the simulation in solving the problem. Based on observations and interviews conducted, it is known that there are four issues: 1.) hospital services 2.) labor allocation (nurses) 3.) capacity and number of rooms/beds 4.) drug supply. Based on the literature search results, it is known that the simulation has the ability to solve these problems. The results of this literature review will then be used as a basis for developing simulation models in hospitals which are the object of research.
\end{abstract}

Keywords : hospital, simulation, discrete-event

\section{Pendahuluan}

Rumah sakit merupakan sebuah sistem yang membutuhkan tingkat efisiensi dan efektifitas yang tinggi. Hal ini dikarenakan entitas (elemen utama) didalam sistem bukanlah produk buatan manusia, melainkan manusia itu sendiri (pasien). Rumah sakit dituntut untuk selalu memberikan pelayanan prima yaitu efektif dan efisien kepada pasien, bahkan dimulai dari sebelum pasien datang ke rumah sakit, saat di rumah sakit sampai saat pasien kembali ke rumah (rawat jalan). Efisiensi dan efektifitas pelayanan rumah sakit sering sekali mengalami kendala dikarenakan tingginya tingkat kompleksitas sistem rumah sakit. Kompleksitas sistem rumah sakit ini dipengaruhi oleh banyaknya variabel probabilistik (tidak pasti) yang bersifat random. Sebagai contoh, rumah sakit tidak bisa memprediksi berapa jumlah pasien yang akan datang, jenis perawatan yang akan diambil, sistem pembayaran yang digunakan, apakah akan rawat inap atau rawat jalan, kapan pasien akan sembuh atau bahkan meninggal. Contoh permasalahan ketidakpastian tersebut akan mempengaruhi keputusan yang harus diambil didalam sistem rumah sakit, seperti kapasitas ruang inap, persediaan obat dan peralatan kesehatan, jumlah sumber daya manusia (dokter, perawat, dan tenaga lainnya), energi, sampai area rumah sakit dan hal lainnya.

Kesalahan dalam pengambilan keputusan dan kebijakan akan mempengaruhi keadaan pasien dan mempengaruhi citra rumah sakit dalam memberikan pelayanan kepada pasien. Rumah sakit yang tidak tepat dalam menentukan berapa jumlah server (dokter, perawat, resepsionis, kasir dan lain lain) akan menimbulkan panjangnya antrian pasien yang seharusnya cepat mendapat penanganan. Dalam hal penyediaan layanan rawat inap, rumah sakit juga sering kali tidak dapat memenuhi permintaan pasien dikarenakan keterbatasan ruangan. Permasalahan lain juga terjadi pada bagian farmasi yang kehabisan persediaan obat atau peralatan dan bahan habis pakai untuk pasien.

Agar sistem rumah sakit berjalan dengan baik untuk mencapai tujuan maka perlu 
dilakukan analisis pada berbagai aspek permasalahan dengan variabel probabilistik tersebut. Rumah sakit harus memiliki sebuah sistem pendukung keputusan yang dapat mengakomodir berbagai macam trade off yang muncul dari keputusan yang diambil. Sistem pendukung keputusan ini juga haruslah sebuah alat yang dapat dengan mudah diimplementasikan, dibaca dan peka terhadap perubahan asumsi. Tidak dipungkiri bahwa semakin hari semakin bervariasi perubahan pada variabel didalam rumah sakit, seperti keluhan pasien, kebijakan pemerintah, perkembangan teknologi, ilmu pengobatan dan semakin banyaknya pusat pelayanan kesehatan lain.

Salah satu alat yang dapat dikembangkan sebagai sebuah sistem pendukung keputusan yang mudah diimplentasian, dibaca dan peka terhadapa perubahan asumsi adalah simulasi. Simulasi merupakan alat penyelesaian masalah didalam sistem dengan cari membuat tiruan atau imitasi dari sistem dan melakukan perbaikan pada model simulasi tanpa mengganggu sistem nyatanya. Dengan menggunakan simulasi, permasalahan tidak hanya dipandang pada satu sisi atau parsial saja namun lebih luas karena melibatkan berbagi komponen didalam sistem. Penelitian ini akan mencoba menyusun sebuah studi pendahuluan tentang aplikasi simulasi sebagai alat pendukung keputusan pada permasalahan di rumah sakit atau sistem pelayanan kesehatan lainnya.

\section{Sistem Rumah Sakit}

Proses pengumpulan data tentang aplikasi simulasi di rumah sakit dilakukan dengan dua metode yaitu observasi langsung pada salah satu rumah sakit yang ada di Yogyakarta dan studi literatur pada penelitian terdahulu. Observasi dilakukan melalui pengamatan secara langsung, wawancara pada pihak rumah sakit dan pengambilan data sekunder jika diperlukan. Observasi dilakukan untuk mengetahui permasalahan yang terjadi didalam sistem. Permasalahan yang terjadi kemudian akan di lakukan konfirmasi pada literatur yang sesuai dengan permasalahan yang dihadapi pada sistem nyata. Observasi dilakukan pada masingmasing bagian rumah sakit. Layout rumah sakit yang digunakan sebagai objek penelitian sesuai pada Gambar 1. Layout dibuat untuk memudahkan dalam memetakan permasalahan di rumah sakit. Dari Gambar 1 dapat diketahui bahwa rumah sakit yang menjadi objek penelitian memiliki bagian-bagian selayaknya rumah sakit pada umumnya.

Aktifitas yang terjadi didalam rumah sakit antara lain adalah kedatangan dan kepulangan pasien, pendaftaran, pemeriksaan, pembayaran, pengambilan obat, pasien rawat inap, pemeriksaan laboratorium dsb. Berdasarkan hasil observasi secara langsung terdapat beberapa kendala yang terjadi antara lain banyaknya pasien yang menunggu atau mengantri, terjadi bottleneck pada beberapa aktfitas, adanya alur pelayanan yang tidak teratur, ruang instalasi gawat darurat yang penuh, ruang tunggu yang tidak cukup menampung pasien sehingga harus ada yang berdiri, dan tata letak kursi tunggu yang tidak terpusat namun di lorong sehingga menganggu jalannya transportasi rumah sakit. Selain observasi, hasil wawancara dan pengambilan data sekunder mendapatkan hasil bahwa terdapat beberapa permasalah di rumah sakit yang sering terjadi diantaranya adalah terjadi kekurangan kapasitas pada bagian IGD dan ICU, kamar rawat inap yang penuh sehingga tidak dapat menampung pasien sehingga terjadi antrian pasien untuk mendapatkan kamar, persediaan obat yang tidak sesuai, serta pengalokasian jumlah tenaga kerja yang belum optimal sehingga sering terjadi komplain pelayanan oleh pasien. 


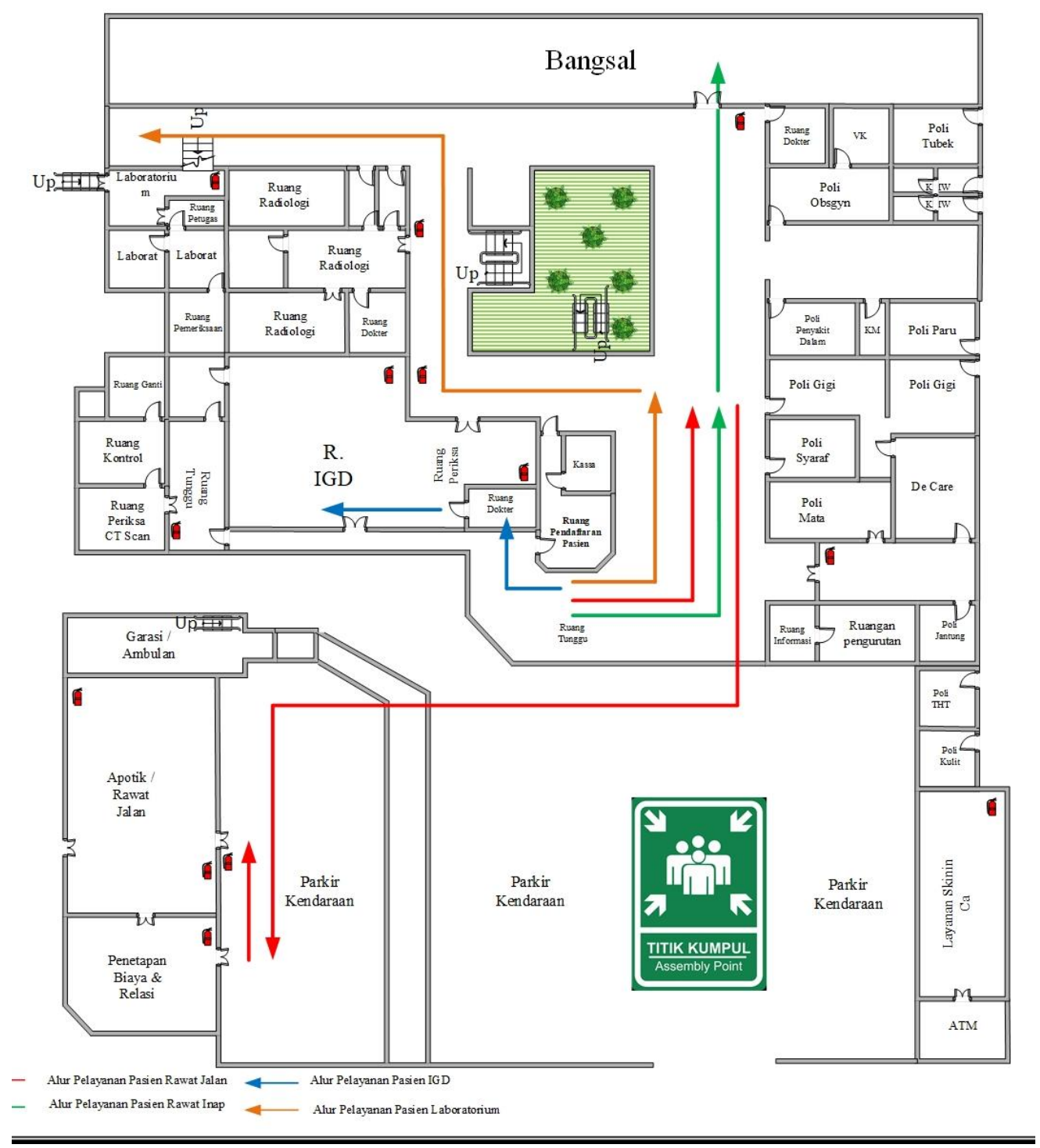

Gambar 1. Layout rumah sakit yang menjadi objek penelitian

Berdasarkan pada uraian diatas maka permasalahan rumah sakit dapat dikelompokkan menjadi beberapa bagian yaitu 1.) pelayanan rumah sakit 2.) alokasi tenaga kerja (perawat) 3.) kapasitas dan jumlah ruang/kamar dan 4.) persediaan obat.

\section{Simulasi Sistem Diskret}

Simulasi didefinisikan sebagai aplikasi untuk menirukan atau merepresentasikan perilaku dari suatu sistem nyata, yang biasanya dilakukan pada komputer dengan menggunakan perangkat lunak tertentu [1]. Simulasi kejadian diskrit atau yang dikenal dengan singkatan DES (Discrete Event Simulation) merupakan suatu pendekatan simulasi dimana perubahan status pada model simulasi terjadi pada titik-titik diskrit tertentu pada suatu waktu yang dipicu oleh suatu kejadian tertentu [2]. Pengembangan model DES umumnya menggunakan bantuan software. Namun, pengembangan model lebih dari sekedar mengetahui bagaimana menggunakan software simulasi. Kunci pengembangan model dalam simulasi terdiri dari 4 (empat) aspek yaitu problem dalam dunia nyata yang dijadikan obyek, model konseptual, model komputer (simulasi), dan solusi atau pemahaman yang dihasilkan [2]. Suryani [3] menjelaskan bahwa dalam melakukan simulasi terdapat beberapa langkah yang perlu dilakukan diantaranya sebagai berikut; 1.) Pendefinisian system, 2.) Formulasi 
model, 3.) Pengambilan data, .4.) Pembuatan model, 5.) Verifikasi model, 6.) Validasi model, 7.) Skenarioisasi, dan 8.) Interpretasi model.

DES merupakan salah satu metodologi dan model dari penelitian operasi yang memungkinkan para pengambil keputusan untuk mengevaluasi efisiensi dari sebuah sistem dengan menjawab pertanyaan "bagaimana jika?". Misalnya, pada permasalahan di rumah sakit, DES dapat digunakan untuk memprediksi atau meramalkan dampak dari perubahan alur pelayanan, penentuan alokasi aset (baik manusia maupun barang), juga untuk menginvestigasi dan menganalisis kompleksitas antar variabel [4]. Gaba [5] mengatakan bahwa simulasi adalah sebuah teknik untuk memperkuat pengalaman yang nyata yang dapat mereplikasi aspek substansial dari sistem nyata dengan cukup interaktif. Simulasi di rumah sakit atau pelayanan kesehatan tergantung dari komitmen dari pengambil keputusan untuk menjadikan hasil simulasi diimplemntasikan di sistem.

\section{DES di Rumah Sakit}

Berdasarkan pada uraian sebelumnya, bahwa berdasarkan hasil observasi dan wawancara diketahui bahwa permasalahan yang terjadi di rumah sakit terbagi menjadi beberapa bagian yaitu 1.) pelayanan rumah sakit 2.) alokasi sumber daya manusia 3.) kapasitas dan jumlah ruang/kamar dan 4.) persediaan obat. Pada bagian ini akan dilakukan pembahasan tentang aplikasi DES pada permasalahan tersebut di rumah sakit.

1.) Pelayanan di rumah sakit

Permasalahan pelayanan di rumah sakit yang menjadi objek penelitian bermacammacam. Dalam hubunganya dengan efektifitas dan efisiensi pelayanan rumah sakit adalah banyak sekali ditemukan pasien yang mengantri cukup lama. Antrian yang mengular ini juga mengakibatkan penggunaan ruang tunggu yang meleibihi kapasitas. Selain itu, tidak adanya ruang mengantri yang khusus bagi masingmasing pelayanan, menyebabkan lorong-lorong rumah sakit menjadi penuh dan mengganggu lalu lintas di rumah sakit. Permasalahan lain adalah alur pelayanan yang kurang teratur dan area yang sempit sehingga membuat pasien harus kembali lagi ke proses sebelumnya. Pramita [6] melakukan sebuah penelitian di rumah sakit yang mempunyai permasalahan panjangnya antrian di sebuah poliklinik penyakit dalam. Simulasi dilakukan untuk mengetahui apakah sistem pendaftaran yang baru saja diterapkan oleh rumah sakit mempunyai pengaruh yang signifikan dalam mengurangi antrian. Berdasarkan simulasi yang dilakukan dengan menggunakan bantuan software ProModel 4.0 dapat diketahui bahwa sistem pendaftaran yang baru dapat mengurangi antrian secara signifikan. Penelitian yang sama juga dilakukan oleh Febianti [7]. Dengan menggunakan bantuan software yang sama yaitu ProModel, Febianti mensimulasikan sistem pelayanan rumah sakit pada beberapa bagian poliklinik. Dengan membangkitkan beberapa alternatif, diperoleh alternatif penambahan loket, eliminasi aktifitas tidak penting dan penambahan papan penunjuk jalan untuk memudahkan pasien terbukti dapat mengurangi antrian pasien. Serupa dengan penelitian sebelumnya, Kharismawati [8] berusaha menghilangkan antrian pada pasien khusus BPJS yang selama ini dikenal mempunyai birokrasi yang cukup rumit. Simulasi yang dilakukan adalah untuk membuktikan hasil implementasi konsep lean pada rumah sakit tersebut, dengan menggunakan bantuan software ProModel. Berbeda dengan penelitian tentang pelayana sebelumnya, Widiatama [9] mensimulasikan alur pelayanan di rumah sakit. Dikarenakan banyaknya aktifitas pasien di rumah sakit, dimulai dari pendaftaran sampai pembayaran, membuat alur pelayanan menjadi rumit jika tidak diatur sedemikian rupa. Penelitian Widiatama mengusulkan beberapa 
alternatif perbaikan alur untuk mempermudah pasien dan membuat sistem lebih efisien.

2.) Alokasi Tenaga Kerja (Perawat)

Permasalahan lain yang ada di rumah sakit yang menjadi objek penelitian adalah pembagian jumlah tenaga kerja, dalam hal ini perawat. Selayaknya rumah sakit pada umumnya, setiap bangsal rumah sakit pasti memiliki perawat dengan aturan shift setiap harinya. Masing-masing jenis bangsal memiliki karakteristik sendirisendiri. Tugas perawat yang tidak hanya merawat pasien namun juga permasalahan administrasi bangsal membuat alokasi perawat dimasing-masing bangsal harus optimal untuk menghindari keluhan pasien dan kelancaran jalannya perawatan pasien. Sarno dan Nenni [10] melakukan penelitian untuk merencanakan jumlah perawat harian pada bangsal di rumah sakit. Penelitian yang dilakukan dengan bantuan software simulasi fleksim ini mengusulkan bahwa akan lebih baik jika rumah sakit mempunya manajemen alokasi perawat yang fleksibel. Dimana jumlah perawat disesuaikan dengan keadaan pasien yang masing-masing memiliki kebutuhan dan alur yang berbeda. Dengan menggunakan model simulasi yang telah dibangun, dapat dilakukan percobaan kebutuhan perawat pada beberapa kondisi yang berbeda.

3.) Kapasitas dan jumlah ruang/kamar

Berdasarkan hasil wawancara dan pengecekan data sekunder, diketahui bahwa beberapa kali rumah sakit terpaksa menolak atau memindahkan kelas rawat inap bagi pasien dikarenakan kamar/ruang yang penuh. Selain kapasitas kamar untuk rawat inap, permasalahan lain adalah kapasitas ruang ICU dan IGD di rumah sakit yang beberapa kali penuh sehingga tidak dapat menampung pasien. Pengembangan model simulasi untuk kapasitas ruang ICU pernah dilakukan oleh Hasibuan dan Bintang [11]. Penelitian tersebut memperhatikan pola kedatangan pasien didalam ruang ICU, ada yang berasa dari IGD, bangsal, Poli dan ruang bedah atau operasi. Penelitian ini mengasumsikan bahwa bed sebagai server yang akan mengolah masukan yaitu pasien. Dengan juga mempertimbangan biaya yang dikeluarkan, simulasi dengan bantuan software Arena ini memberikan usulan jumlah bed yang optimal berdasarkan alternatif yang ditawarkan. Daniels [12] menggunakan simulasi sebagai alat untuk memprediksi ketersediaan bed di rumah sakit sampai 2 (dua) hari kedepan. Hasil penelitian ini menunjukkan bahwa simulasi dapat digunakan untuk memprediksi ketersediaan bed untuk jangka pendek, dengan catatan data dari pihak rumah sakit tersedia dan akurat.

4.) Persediaan Obat

Pada dasarnya permasalahan persediaan di rumah sakit tidak hanya tentang persediaan obat, namun obat menjadi sebuah entitas vital bagi pasien di rumah sakit. Sehingga, fokus permasalahan persediaan adalah pada obat. Hal ini juga terjadi di rumah sakit yang menjadi objek penelitian. Sering kali rumah sakit mengalami kekurangan persediaan obat sehingga pasien harus membeli diluar rumah sakit. Wirdiyanto [13] menggunakan simulasi untuk membandingkan beberapa sistem persediaan yang diusulkan untuk diimplementasikan. Masingmasing usulan sistem persediaan dipilih berdasarkan pada tingkat service level yang tinggi dan biaya yang dibutuhkan. 


\section{Kesimpulan}

Simulasi mempunyai beberapa fungsi diantaranya sebagai alat untuk merancang, mengevaluasi, memprediksi, serta mencari jawaban terbaik dari beberapa alternatif. Pada permasalahan di sistem rumah sakit dapat diketahui bahwa simulasi dapat diaplikasikan untuk menyelesaikan permasalahan yang berhubungan dengan peningkatan performansi rumah sakit agar efektif dan efisien. Penelitian selanjutnya akan mengusulkan untuk membangun sebuah model simulasi sistem di rumah sakit yang menjadi objek penelitian yang tidak hanya menyelesaikan permasalahan secara parsial namun secara menyeluruh sehingga dapat dicapai sistem rumah sakit yang efektif dan efisien.

\section{Daftar Pustaka}

[1] Law, A. M., Kelton, W. D., \& Kelton, W. D. (2000). Simulation modeling and analysis (Vol. 3). New York: McGraw-Hill.

[2] N. Siswanto., E. Latiffianti., \& E. Wiranto, Stefanus. (2017). Simulasi Sistem Diskrit. Its Tekno Sains. Surabaya

[3] Suryani, E. (2006). Pemodelan \& Simulasi. Yogyakarta: Graha Ilmu.

[4] Jun, J. B., Jacobson, S. H., \& Swisher, J. R. (1999). Application of discrete-event simulation in health care clinics: A survey. Journal of the operational research society, 50(2), 109-123.

[5] Gaba, D. M. (2004). The future vision of simulation in health care. BMJ Quality \& Safety, 13(suppl 1), i2-i10.

[6] Sari, D. P., \& Asih, A. M. S. (2017). Simulasi Antrian Untuk Appointment Scheduling Pada Sistem Pelayanankesehatan (Studi Kasus Poliklinik Penyakit Dalam). Jurnal Teknosains, 5(1), 49-60.

[7] Febianti, E., Muharni, Y., \& Mustikawati, E. A. (2018). Pendekatan Lean Healthcare Dan Simulasi Untuk Meminimasi Waktu Pelayanan Rawat Jalan Di RSUD X. Jurnal Industrial Servicess, 4(1).

[8] Kharismawati, A., \& Herliansyah, M. K. (2016). Implementasi lean healthcare pada pasien bpjs rawat jalan di rumah sakit bethesda yogyakarta. In Seminar Nasional Teknik Industri Universitas Gajah Mada (pp. 408-417).

[9] Widiatama, Y. (2018). Simulasi Perbaikan Alur Pelayanan Pasien Rawat Jalan Dengan Pendekatan Lean Hospital Pada Rumah Sakit Umum (RSU) Kabupaten Tangerang. JITMI (Jurnal Ilmiah Teknik dan Manajemen Industri), 1(1), 37-49.

[10] Sarno, D., \& Nenni, M. E. (2016). Daily nurse requirements planning based on simulation of patient flows. Flexible Services and Manufacturing Journal, 28(3), 526549.

[11] Hasibuan, A., \& Bintang, M. (2005). Pengembangan Model Simulasi Untuk Perencanaan Kapasitas Unit Perawatan Intensif (ICU).

[12] Daniels, M. J. (2004). Forecasting hospital bed availability using computer simulation and neural networks.

[13] Wirdianto, E., Syaflinda, M., \& Milana, M. (2019). Evaluasi Model Perencanaan Persediaan Obat dengan Pendekatan Simulasi. INVOTEK: Jurnal Inovasi Vokasional dan Teknologi, 19(1), 53-66. 